\title{
Lung Imaging in Acute Lung Injury and Acute Respiratory Distress Syndrome with PET
}

\author{
Jean-Christophe Richard ${ }^{*}, 1,2$, Céline Pouzot ${ }^{2,3}$, Claude Guerin ${ }^{1,2}$
}

\author{
${ }^{I}$ Hospices civils de Lyon, Service de Réanimation Médicale et d'Assistance Respiratoire, Hôpital de la Croix Rousse; \\ Université de Lyon, Université Lyon 1, Lyon, France \\ ${ }^{2}$ CREATIS (CNRS UMR 5515 et INSERM Unité 630), Lyon, France \\ ${ }^{3}$ Service de Soins Intensifs Animaux et Medecine d'Urgence, Ecole Nationale Vétérinaire de Lyon, Marcy l'etoile, \\ France
}

\begin{abstract}
PET imaging is an attractive technique to study patients with acute lung injury (ALI) and acute respiratory distress syndrome (ARDS) because of its non-invasiveness, its potential to obtain quantitative measurements on a regional basis, and its ability to give functional (not simply morphologic) information about the lungs. The purpose of this manuscript is to focus on the application of PET imaging in ALI/ARDS, to review PET measurements of potential interest in this context and to address their limitations, and finally to summarize the contribution of previous studies in ALI/ARDS patients in the understanding of the physiopathology of this syndrome.
\end{abstract}

Keywords: ARDS, positron emission tomography, ventilation, perfusion, inflammation.

\section{INTRODUCTION}

Despite active research, mortality in acute respiratory distress syndrome (ARDS) remains a high as 40 to $60 \%$ [1]. Understanding the complex physiopathology of acute lung injury is further complicated by the wide spectrum of clinical conditions leading to this syndrome [2]. Physiopathologic studies are hindered by extreme spatial heterogeneity of lung lesions during ARDS, which may only be apprehended by imaging. While computed tomography has become the gold standard for ARDS imaging since pioneering studies by Gattinoni's group (reviewed in reference [3] and subject of another chapter in present issue), its contribution to a better understanding of ARDS physiopathology is indisputable but restricted to physiological parameters influencing physical density (alveolar recruitment or derecruitment, lung hyperinflation, edema). Furthermore, none of the key physiopathologic processes identified in the ARDS definition [4] (namely lung inflammation and vascular permeability among others) can be directly or indirectly assessed by CT. PET imaging is therefore an attractive technique to study ARDS because of its non-invasiveness, its potential to obtain quantitative measurements on a regional basis, and its ability to give functional (and not simply morphometric) information on lung status. To our knowledge, while several excellent reviews have addressed the evaluation of lung function with PET [5-9], none focused specifically on ARDS. The purpose of this manuscript is to address the specific application of PET imaging in ARDS patients, to review PET measurements of potential interest in this context and to address their limitations, and finally to

*Address correspondence to this author at the Service de Réanimation Médicale et d'assistance Respiratoire, 103 Grande Rue de la Croix Rousse, 69004 Lyon, France; Tel: (+33) 4720717 62; Fax: (+33) 4720717 74;

E-mail: j-christophe.richard@chu-lyon.fr summarize the contributions of previous studies done in ARDS patients to better understand the physiopathology of this complex syndrome.

\section{CHALLENGES PERTAINING TO ARDS LUNG IMAGING WITH PET}

Several challenges must be overcome to obtain reliable quantitative PET measurements in the lung. These include artifacts from respiratory movement, influence of regional lung aeration on radioactivity level, and increased background radiation in relation to high pulmonary blood volume. These problems have been reviewed elsewhere [7, $10]$ and will not be discussed.

In the perspective of imaging the ARDS lung with PET, a critical point is to adapt the imaging protocol to the clinical status of ARDS patients. An ideal technique must therefore avoid any patient-ventilator disconnection to prevent alveolar derecruitment and procedure-related physiological modifications that may decrease the pertinence of subsequent PET measurements. For similar reasons, imaging protocols should avoid prolonged breath holding. Since ARDS is a particularly unstable disease, image acquisition should be as short as possible to avoid variations of PET parameters, since patient stability is a prerequisite of most imaging protocols (if not all). Clinical characteristics of ARDS patients may require substantial modifications to the PET imaging protocol. For example, renal failure is observed in up to $75 \%$ of ARDS patients [11], and may interfere with tracer dose, image acquisition procedure or background radioactivity level when using a tracer with renal elimination such as $\left[{ }^{18} \mathrm{~F}\right]$-fluorodeoxyglucose $\left(\left[{ }^{18} \mathrm{~F}\right]-\mathrm{FDG}\right)[12]$.

Other critical problems to deal with are related to specific physiopathologic status of ARDS patients. Severe hypoproteinemia or high tracer distribution volume are frequently observed in this context and may interfere with 
tracer kinetics. Patient cooperation during imaging is usually not an issue during the initial phase of ARDS, considering the near constant need of sedation, analgesia and neuromuscular blockade, but may be problematic if imaging is planned during the weaning process. Furthermore, since ARDS is a rapidly evolving disease, imaging ARDS requires some standardization in the timing of the measurements, and often imposes unscheduled studies and flexibility in radiotracer and/or cyclotron availability. Whatever the PET measurement, model validity must be verified over a wide range of cardiac output (and hence pulmonary blood flow), since ARDS patients may exhibit heterogeneous cardiac status, from hyperdynamic states to heart failure. Mechanical ventilation should be standardized during PET images acquisition, and ideally PET measurements have to be normalized for regional lung inflation.

One pratical issue to make easier is patient transport to the PET facility. For safety reasons, this transport is conceivable for the less severe patients; however, the potential benefits must be carefully weighed against the risks of transporting less stable patients, such as those with uncontrolled hypoxemia in supine position, those who require extracorporeal membrane oxygenation, and those who have unstable haemodynamics or require continuous dialysis support. During transport and throughout the imaging procedure, a physician and possibly a nurse must be present to provide for continuous critical care to the patient. Ultimately, wide diffusion of combined PET/CT devices may facilitate ARDS imaging with PET since clinical management of ARDS often requires thoracic CT scan, eliminating reluctance to patient transport for the sole purpose of PET imaging. Once a clear benefit to transport ARDS patients to PET facilities is demonstrated, the issue of transportation will be solved.

\section{PET MEASUREMENTS OF INTEREST DURING ARDS}

\section{Pulmonary Blood Flow (PBF)}

PBF has previously been assessed with PET using intravenous (i.v.) oxygen-15 radiolabelled water $\left(\mathrm{H}_{2}{ }^{15} \mathrm{O}\right)$ [13], i.v. ${ }^{68}$ Ga-albumin macroaggregates (MAA) [14], or i.v. ${ }^{13} \mathrm{~N}$-labeled $\mathrm{N}_{2}$-saline [15].

Lung $\mathrm{H}_{2}{ }^{15} \mathrm{O}$ tracer kinetics has been modeled with both static and dynamic monocompartmental models and successfully validated using radiolabelled i.v. injected microspheres as gold standard in normal animals [16, 17], healthy volunteers [14], and heart failure patients [14]. Due to the short half life of $\mathrm{H}_{2}{ }^{15} \mathrm{O}(2 \mathrm{~min})$, this technique is particularly suitable for multiple measurements of PBF over short periods of time. Unlike perfusion measurements in other organs with this tracer, the blood-tissue partition coefficient for water $(\lambda)$ in the lung cannot be assumed, since it is dependent on regional lung inflation (or density), and must be added to PBF as model parameters.

Mathematical model resolution requires determination of both pulmonary arterial blood (lung input function) and lung concentration (tissue response) of the tracer. While lung tracer concentration is measured non-invasively with PET, lung input function was initially invasively assessed by multiple blood samplings through a pulmonary artery catheter [13]. However, it was later shown that non-invasive measurement of right ventricle $\mathrm{H}_{2}{ }^{15} \mathrm{O}$ radioactivity with PET was a reliable estimate of lung entry function in pigs [17], and validity of this non-invasive measurement can reasonably be assumed in humans. The static model, extensively studied by Daniel Schuster's group [13], does not account for changes in tracer concentration over time and requires a first PET image following bolus injection of $\mathrm{H}_{2}{ }^{15} \mathrm{O}$, and a second image at tracer equilibrium to estimate $\lambda$. Model robustness has been extensively studied by this group $[13,18]$, and has been shown very high, except in condition combining low lung density (i.e. low $\lambda$ ) and high PBF. This model is then particularly suitable to study acute lung injury and ARDS, as it does not require high computational needs by virtue of simplicity and, hence, is particularly suitable for voxel-by-voxel analysis of PET data. To try to overcome some of the limitations of the static model, a dynamic model has been proposed. This modeling takes into account change of tracer radioactivity over time and tracer transit time through lung tissue (Fig. 1) [17]. Model accuracy was good, but sensitivity analysis demonstrated that bias in PBF could be important in situations of both high flow and high tracer lung transit time, a circumstance very unlikely within the lungs [17]. Finally, when monocompartmental model validity is challenged, PBF can be assessed with i.v. ${ }^{68} \mathrm{Ga}$-albumin (MAA) using a model-free method, although the longer half-life of Gallium68 (68 min) might make certain experimental protocols impractical [14].

PBF can also be assessed using ${ }^{13} \mathrm{~N}-\mathrm{N}_{2}$-saline using a model-free method [15]. This tracer is administered intravenously during a brief 20-30-s apnea. As tracer enters lung capillaries, virtually all ${ }^{13} \mathrm{~N}-\mathrm{N}_{2}$ diffuses through the alveolar space because of nitrogen's low blood-gas partition coefficient, and accumulates proportionally to regional perfusion [15]. Quantitative analysis of ${ }^{13} \mathrm{~N}-\mathrm{N}_{2}$ radioactivity with PET in a lung region, normalized to whole-slice lung radioactivity, leads to the regional fractional $\mathrm{PBF}$ of this lung region. However, in lungs with aeration abnormalities such as atelectasis or edema, ${ }^{13} \mathrm{~N}-\mathrm{N}_{2}$ is not retained during breath hold and is cleared by shunting blood [19]. Under this circumstances, regional lung perfusion can no longer be estimated by end-apnea lung radioactivity, but remains related to peak regional lung radioactivity usually observed 5-10 sec after tracer injection [20]. Venegas group has nicely refined this technique using either a three [19] or a fourcompartment [21] model to assess regional PBF, shunt fraction and specific ventilation, that have been shown to accurately fit lung ${ }^{13} \mathrm{~N}-\mathrm{N}_{2}$ kinetics during experimental acute lung injury $[21,22]$, at the price of intense computational requirements. A potential drawback of this technique is the requirement of apnea, a potentially harmful procedure in the perspective of application of this technique in acute lung injury/ARDS patients.

\section{Alveolar Ventilation}

Ventilation may be assessed with PET using radiotracers with low blood-tissue partition coefficient (i.e. low blood solubility), administered either by inhalation $\left({ }^{13} \mathrm{~N}-\mathrm{N}_{2}[23\right.$, $\left.24],{ }^{19} \mathrm{Ne}[25]\right)$ or intravenously $\left({ }^{13} \mathrm{~N}-\mathrm{N}_{2}\right.$ dissolved in saline [15]). 

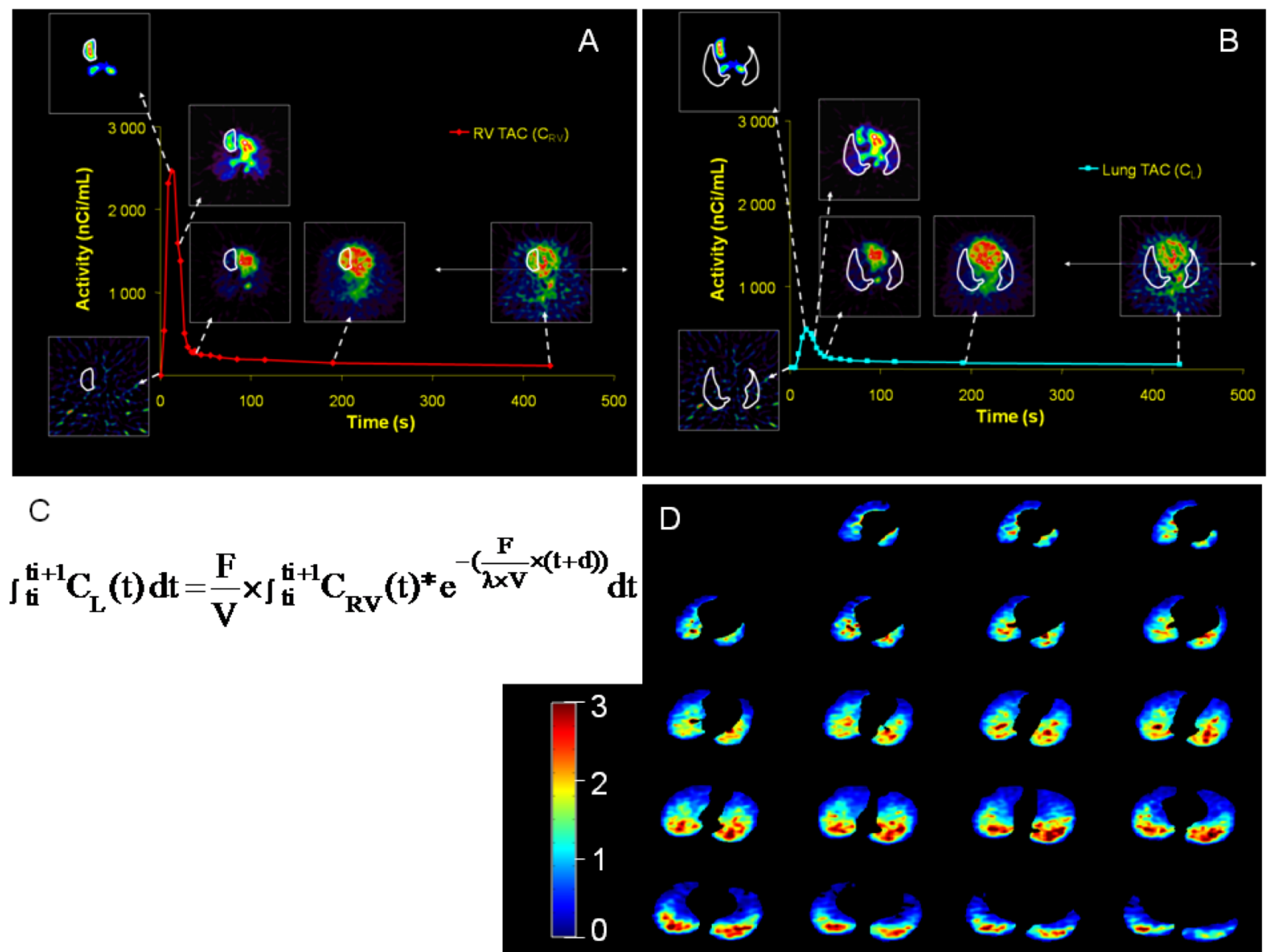

1
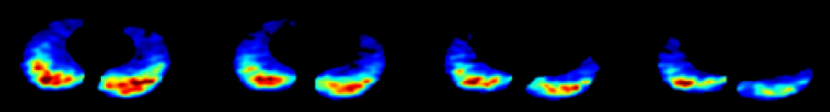

Fig. (1). Assessment of pulmonary blood flow with PET and $\mathrm{H}_{2}{ }^{15} \mathrm{O}$. (A) Right ventricle time activity curve (entry function). (B) Lungs time activity curve. (C) Dynamic model equation [17]. (D) Parametric images of pulmonary blood flow. Pulmonary blood flow is determined by compartmental modeling in each lung voxel and normalized by its mean value over the whole lung to account for differences in cardiac output between subjects. Therefore, a voxel assigned to a perfusion value of 1 has a perfusion equal to the mean perfusion value over the whole lung. $C_{L}(t)=$ Lung radioactivity at time $t ; C_{R V}(t)=$ right ventricle radioactivity at time $t ; d=$ tracer transit time between right ventricle and lung; $F / \mathrm{V}=$ pulmonary blood flow; $\lambda=$ blood-tissue partition coefficient for water.

${ }^{13} \mathrm{~N}-\mathrm{N}_{2}$ inhalation may be performed either in a closedloop circuit of an anesthesia ventilator [26, 27], or through the inspiratory limb of a standard ICU ventilator [28]. Quantitative analysis of ventilation with either methods is based on compartmental modeling of ${ }^{13} \mathrm{~N}-\mathrm{N}_{2}$ kinetics during tracer washout, with one or two compartment (Fig. 2). The bi-compartmental model is required to fully account for ventilation heterogeneity within regions of interest, especially in acute lung injury [28, 29]. External validation of this technique has been successfully performed in different conditions of minute-ventilation set at the ventilator, that have been shown to closely correlate with PET measurements of ventilation in animals during both normal condition and experimental acute lung injury [28]. The main drawback of this technique is that it cannot differentiate between alveolar dead space ventilation and alveolar ventilation.

The i.v. injection of ${ }^{13} \mathrm{~N}-\mathrm{N}_{2}$ in saline allows determination of ventilation at the end of the short apnea required for tracer accumulation within the airspaces (see above). As ventilation is resumed, tracer washout from the lung may be modeled with a mono or a bi-compartmental to assess alveolar ventilation [29]. The main advantage of this technique is that it can also assess ventilation-perfusion (VA/Q) relationships on a voxel-by-voxel basis [29-31], without requiring additional tracer injection. External validation has been performed in sheeps in 3 experimental conditions (pulmonary embolism, lung lavage and bronchoconstriction), and clearly showed that predicted $\mathrm{PaO} 2$ and $\mathrm{PaCO} 2$ calculated from $\mathrm{PET}$ regional measurements of $\mathrm{VA} / \mathrm{Q}$ were reliable estimates of measured arterial blood gas values [29]. Potential drawbacks are requirement of apnea, practical difficulty to produce a high yield ${ }^{13} \mathrm{~N}-\mathrm{N}_{2}$ saline solution [32], and impossibility to assess ventilation in dead space distal areas [33]. This method is then particularly suitable to study physiopathology of gas exchange, but may be less adequate to study regional ventilation pattern in regions with low perfusion. 


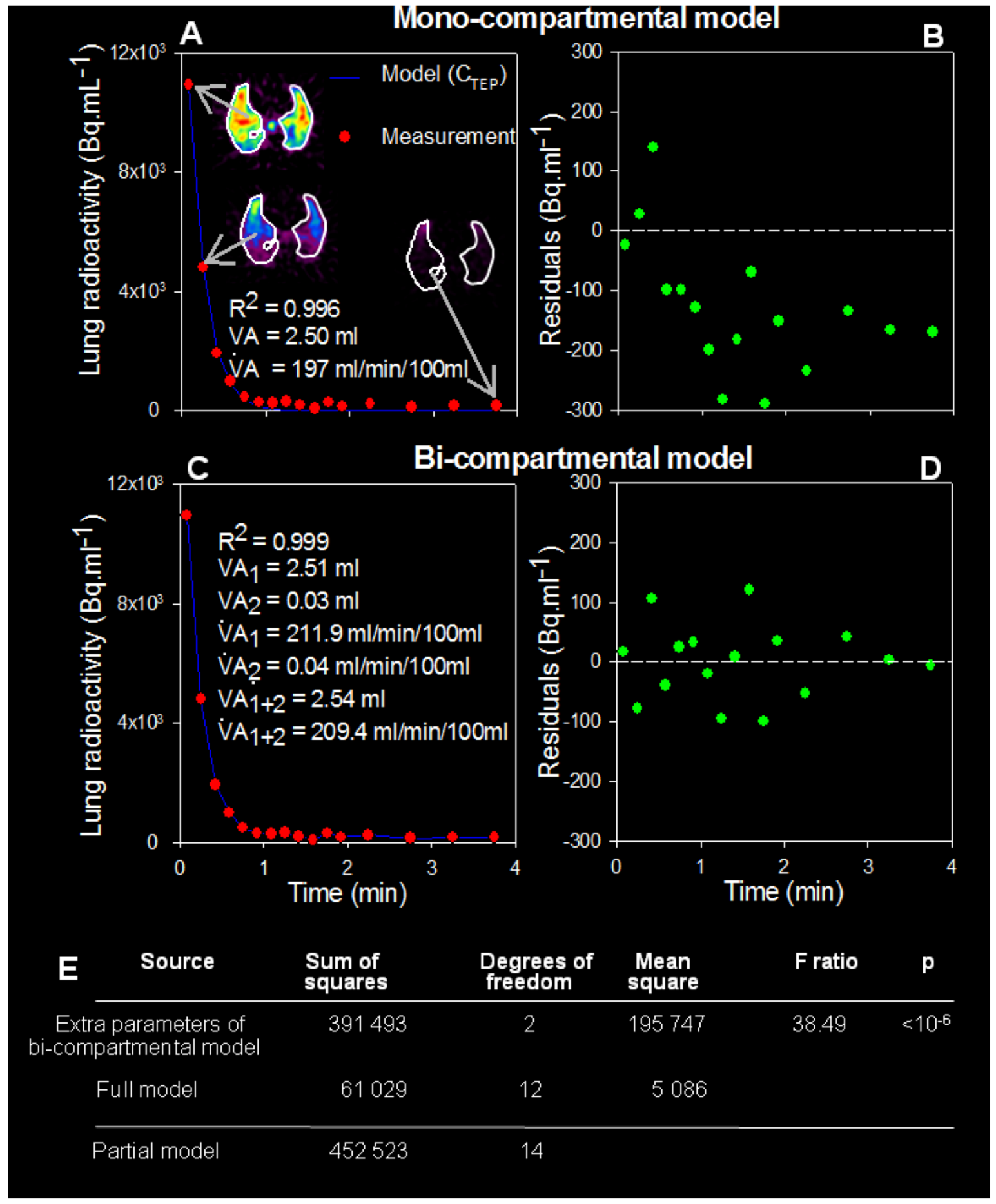

Fig. (2). ${ }^{13} \mathrm{~N}-\mathrm{N}_{2}$ kinetics during washout and compartmental modeling in a normal pig at mid-chest level. Red circles are time-activity curve data points obtained with PET. Continuous blue lines are fitted data using mono (A) or bi-compartmental (B) models as described in reference [28]. (B) and (D) are corresponding plots of residuals over time. (E) shows extra sum of square analysis for nested models as a way to compare models relevance. In this example, bi-compartmental is statistically superior to mono-compartmental model as shown by residuals distribution and extra-sum of square analysis. Bi compartmental modeling identify a fast compartment with volume $\mathrm{VA}_{1}$ and ventilation $\dot{V}_{A_{1}}$ and a slow compartment with volume $\mathrm{VA}_{2}$ and ventilation $\dot{V}_{A_{2}}$.

Alveolar Volumes, Gas Fraction and Alveolar Recruitment

Assessing regional alveolar volumes is fundamental in ARDS for several reasons. Lung aeration is dramatically reduced in ARDS, to an extent usually qualified as "baby lung" [34], and knowledge of aerated compartment size may help to tailor tidal volume to the effective aerated volume during mechanical ventilation, in order to avoid tidal hyperinflation. Furthermore, detection of regional alveolar anatomic recruitment (i.e. re-aeration of previously atelectatic lung regions) after any ventilatory intervention may help to tailor the right level of end-inspiratory or end- 
expiratory pressure in order to improve oxygenation without adverse side effects. Indeed, tidal hyperinflation and repetitive intra-tidal recruitment-derecruitment have been implicated in ventilator-induced lung injury [35], and direct detection of these phenomenon at a regional level can be done by imaging only.

Regional aerated volumes (VA) can be assessed with PET using either transmission images [15, 28, 36], inhaled ${ }^{13} \mathrm{~N}-\mathrm{N}_{2}$ at tracer equilibrium [33], or during washout using compartmental modeling [28]. Assessment of regional aerated volumes using transmission scans relies on the close correlation between lung density (LD) and lung attenuation [37], using the following equation [36]:

$\mathrm{VA}=1-\mathrm{LD} / 1.04$

Equation 1

With inhaled ${ }^{13} \mathrm{~N}-\mathrm{N}_{2}$, regional gas fraction is first assessed by normalizing lung radioactivity at tracer equilibrium measured with PET within a region of interest (ROI) to specific activity of a sample of inhaled gas [33]. Aerated volume can then be assessed by multiplying gas fraction by ROI volume. Finally, aerated volumes may be assessed as model parameters during inhaled ${ }^{13} \mathrm{~N}-\mathrm{N}_{2}$ washout [28], and have been shown to closely correlate with aerated volumes assessed with transmission scan [28]. However, transmission-derived aerated volumes systematically underestimates aerated volumes by approximately $10 \%$ [28], mainly in relation with partial-volume averaging effect of high density structures surrounding the lungs. All the preceding techniques need several dozens of seconds or minutes of acquisition to obtain images of acceptable signalto-noise ratio, and then are performed in dynamic conditions during breathing. Aerated volume assessed with PET with this particular methodology is then an estimate of mean aerated volume over the respiratory cycle. However, assessment of end-expiratory or end-inspiratory aerated volume is theoretically possible with PET, using respiratory gating, providing substantial increase in duration of image acquisition to increase counting statistics.

PET may also quantify alveolar recruitment [38], defined as re-aeration of previously atelectactic lung regions, by adaptation of a method previously validated with computed tomography $[39,40]$. Using voxel-by-voxel analysis on PET transmission scans, a non-inflated compartment may be defined as voxels with density ranging from 0.9 to 1.1 , and non-inflated tissue weight is then computed by multiplying volume by mean density of this compartment (Fig. 3). Recruitment between two ventilatory conditions, may finally be defined as decrease in non-inflated tissue weight between each condition. Validation of this technique was demonstrated by an excellent agreement with alveolar recruitment assessed from volume-pressure curve as a reference [38]. However, with wide diffusion of hybrid PET/CT devices, radioisotope attenuation correction will probably be no longer available and alveolar recruitment be more accurately defined using $\mathrm{CT}$, provided misregistration between PET and CT scans is managed. PET has also the unique potential to assess functional recruitment, defined as improved regional shunt fraction through restored aeration to well-perfused lung units. This measurement is critical since alveolar recruitment of unperfused ventilatory units is of limited interest, if any. In an experimental model of lung injury, Musch et al. showed that increased regional aeration by PEEP in some lung regions failed to coincide with functional recruitment assessed with PET and i.v. ${ }^{13} \mathrm{~N}-\mathrm{N}_{2}$ [41], nicely demonstrating that improved regional shunt fraction occurs only in lung regions where improved aeration outweigh the detrimental effect of the PEEP to shift the regional perfusion to the dorsal lung regions.

\section{Pulmonary Vascular Permeability and Extravascular Lung Water}

Increased pulmonary vascular permeability and extravascular lung water (EVLW) are landmark features of ARDS [4], and are independent predictive factors of mortality [42]. Pulmonary vascular permeability estimates the degree of injury of the alveolar-capillary membrane during ARDS, and hence may be viewed as a method of quantifying severity of acute lung injury. With PET, pulmonary vascular permeability is assessed by quantification of the rate at which radiolabeled proteins injected intravenously accumulate in the extravascular compartment. It is usually expressed as a pulmonary transcapillary escape rate (PTCER) [16]. PTCER is computed as the ratio of $\mathrm{k} 1$ (vascular-to-extravascular forward rate constant of a bicompartmental model describing radiolabeled proteins kinetics in the lung) over regional plasma volume (an output of compartmental modeling taken as surrogate of the surface area available for protein transport) [16]. Both ${ }^{68} \mathrm{Ga}-$ transferrin and ${ }^{11} \mathrm{C}$-methylalbumin have been used as protein tracers for PET imaging of PTCER, and are equally reliable [43]. External validation of these techniques was performed by demonstrating a close correlation between PET estimates of PTCER and extent of injury of the alveolar-capillary membrane at the electron-microscopic level [44]. However, reliability of these techniques may be doubtful in certain circumstances: low pulmonary blood flow [45], changes in vascular volume during PET data acquisition [46], or inclusion of non-capillary blood vessels in PET regions of interest [46].

\section{Total and Extra-Vascular Lung Water}

EVLW is assessed with PET in two steps. First, total lung water (TLW) is quantified using a tracer that diffuses freely into the extravascular compartment $\left(\mathrm{H}_{2}{ }^{15} \mathrm{O}, \mathrm{C}^{15} \mathrm{O}_{2}\right)$. Following i.v. injection, 3-4 minutes are required for tracer equilibration between vascular and extravascular spaces, especially in areas of low blood flow. Pulmonary and blood radioactivity are then measured with PET after placement of ROIs in the lung and the right ventricle, respectively, and TLW is computed as follows:

TLW (ml/100ml lung) $=84 \times$ Activity $_{\text {Lung }} /$ Activity $_{\text {Blood }}$ Equation 2

with 84 a factor assumed to represent water content of 100 $\mathrm{ml}$ of whole blood [47].

The second step relies on evaluation of intravascular lung water (ILW), by using an erythrocyte (inhaled $\mathrm{C}^{15} \mathrm{O}$ or ${ }^{11} \mathrm{CO}$ ), or a plasma marker $\left({ }^{68} \mathrm{Ga}\right.$-transferrin). ILW is then computed as follows:

ILW $(\mathrm{ml} / 100 \mathrm{ml}$ lung $)=$

$84 \times$ Activity $_{\text {Lung }} /($ Activity Blood $\times \mathrm{R})$

Equation 3

with $\mathrm{R}$ a correction factor, accounting for the lower value of lung relative to peripheral blood hematocrit, with a value of 0.9 in humans [48]. 

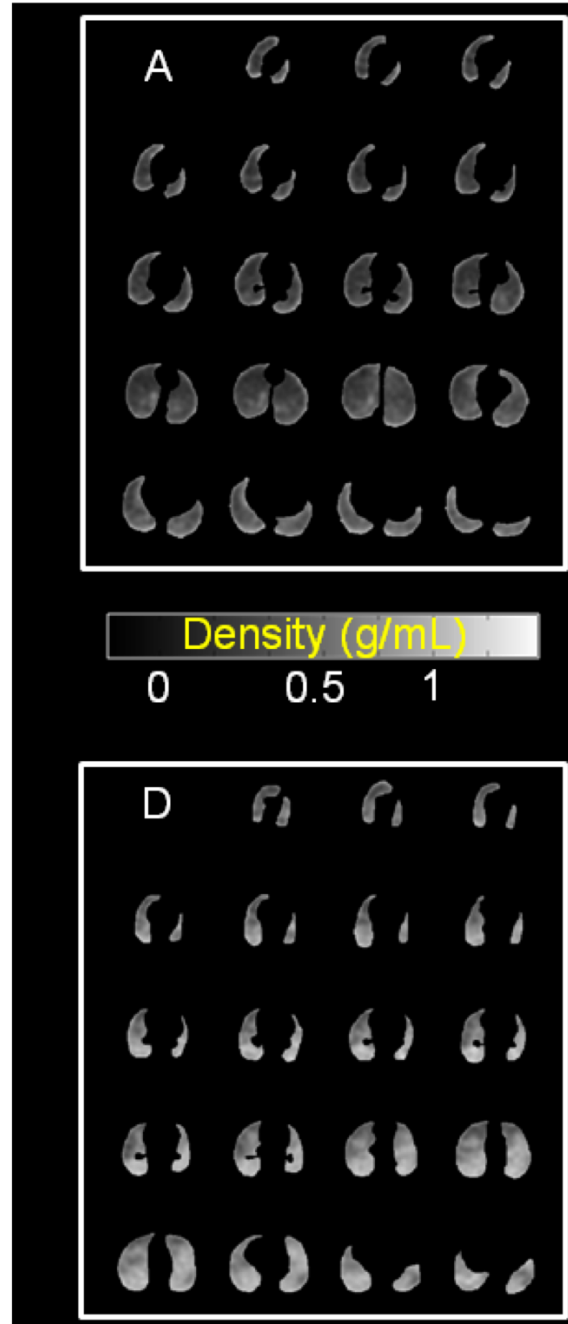
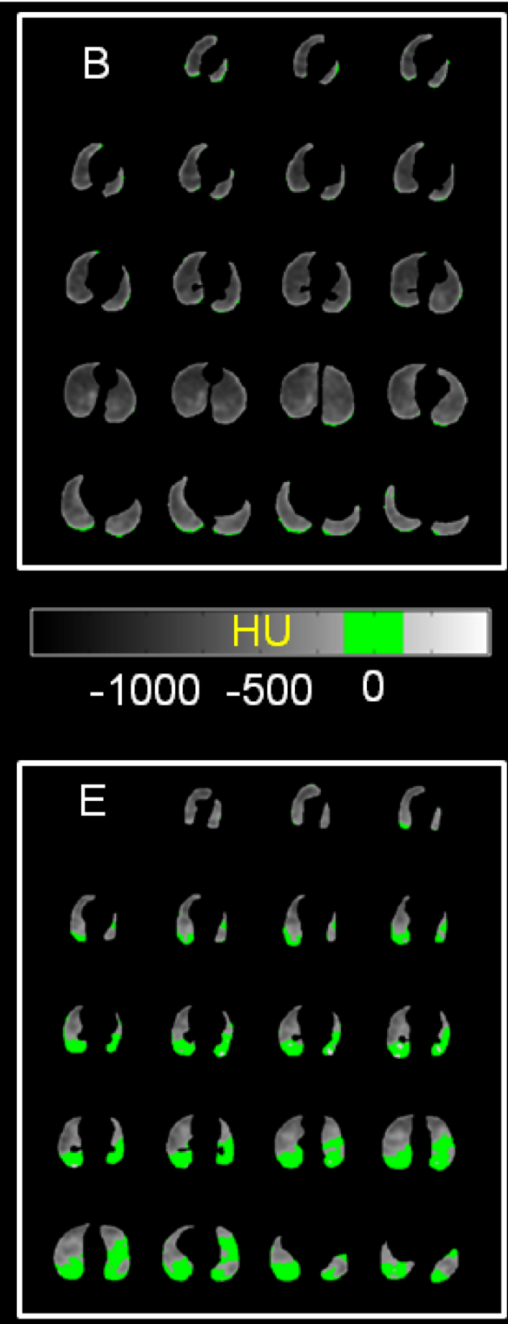

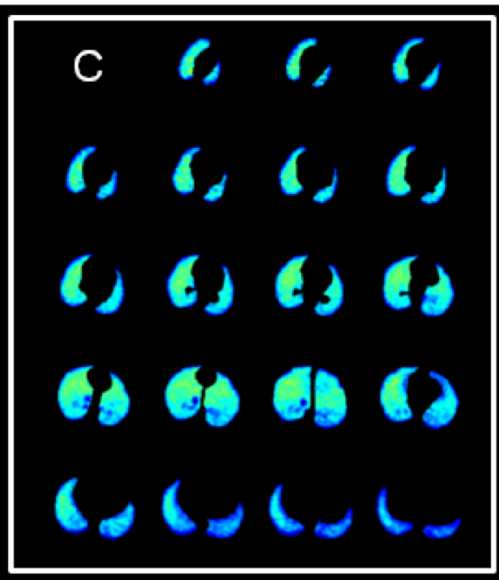

Aerated volume (ml/voxel)

0

$0.01 \quad 0.02$ 0.03

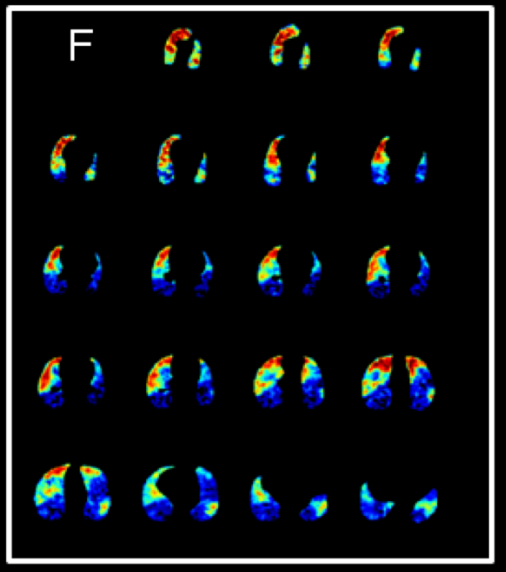

Fig. (3). Parametric images of lung density (panels $\mathbf{A}$ and D), derecruitment (panels $\mathbf{B}$ and E) and aerated volume calculated with compartmental modeling of 13N-N2 washout (panels $\mathbf{C}$ and $\mathbf{F}$ ) in a normal pig (upper panels) and a pig with lung injury (lower panels) lying supine. Density images are color scaled as a function of density calculated from transmission scan. Derecruitment images are color scaled as a function of density calculated from transmission scan and expressed in Hounsfield units (HU). Green voxels are non-aerated voxels (with UH ranging from -100 to +100 ). Aerated volume images are color scaled as a function of aerated volume expressed in ml per voxel, and calculated with compartmental modeling as described in reference [28]. Images are horizontal slices (19 per acquisition), laying from most cranial to most caudal parts, using the radiological convention (meaning left lung in on the right side of each slice). As clearly shown in the normal pig, there are scarce non-aerated voxels mainly located in the caudal regions. To the opposite, the lung injured pig express massive derecruitment (non-aerated voxels), predominantly in the dependent dorsal regions in the supine position.

EVLW is then finally computed as the difference between TLW and ILW. The validity of EVLW may be challenged in ARDS since extensive capillary thrombosis may hinder tracer arrival in some lung areas, and tracer equilibration may not be achieved in areas of low PBF $(<50$ $\mathrm{ml} / \mathrm{min} / 100 \mathrm{ml}$ lung). This may underestimate TLW and EVLW by more than $20 \%$ [49]. However, PET measurement of EVLW highly correlated with gravimetric estimates of EVLW in experimental lung injury, despite a systematic underestimation approximating $10-15 \%[50,51]$. Finally, PET estimates of EVLW are highly reproducible, behave linearly when lung water increase over a 20-fold concentration range, and are highly sensitive since as little as $1 \mathrm{ml}$ additional EVLW can be detected [51].

Extravascular density (EVD) is a close surrogate of EVLW [49] and can be calculated as follows. Total LD is first assessed using transmission scan. The intravascular component of lung density (IVD) is then estimated, like ILW, using erythrocyte or plasma markers $[52,53]$ :

$\mathrm{IVD}=1.06 \times$ Activity Lung $/\left(\right.$ Activity $\left._{\text {Blood }} \times \mathrm{R}\right) \quad$ Equation 4

with 1.06 the physical density of blood and $\mathrm{R}$ the correction factor for lung hematocrit (see above). EVD is then computed as the difference between total LD and IVD [52, 53]. EVD overestimates EVLW by approximately $10-15 \%$, but is independent on regional PBF [49]. However, this measurement may be flawed since it cannot differentiate an increase in lung density related to water retention from an accumulation of inflammatory cells or lung fibrosis. Since dedicated PET scanners are progressively phased out and replaced by PET/CT devices, measurement of EVD will require in the future a combined measurement of total $\mathrm{LD}$ with CT and IVD with PET. While measurement of lung density with CT is closely related to lung density 
measurement with PET [37], combining data from multiple imaging modalities with different spatial resolutions and acquisition times may lead to misregistration and interfere with measurement validity. New technical solutions coping with these issues have recently been reviewed elsewhere [54, 55].

\section{Lung Inflammation and Fibroproliferation}

Lung inflammation is a cardinal feature of the physiopathology of ARDS [2], and may be involved in multi-organ failure (one of the main cause of death in ARDS patients) if pro-inflammatory mediators are decompartmentalized from the lung. Furthermore, excessive or unresolving lung inflammation may be a trigger for lung fibroproliferation and unfavorable evolution to persistent ARDS. Finally, recent studies have clearly linked inappropriate ventilatory settings and increased pulmonary inflammation [56], resulting in increased mortality in ARDS patients [57]. Assessment of lung inflammation in ARDS is then critical, but hindered by the invasiveness of current reference diagnostic procedure (assays of pro-inflammatory mediators in bronchoalveolar lavage (BAL)) and by the spatial heterogeneity of ARDS which cannot be reliably apprehended by BAL. Non-invasive evaluation of lung inflammation with PET offers the potential advantages of being non-invasive, of assessing regional heterogeneity, and of using $\left[{ }^{18} \mathrm{~F}\right]$-fluorodeoxyglucose $\left(\left[{ }^{18} \mathrm{~F}\right]-\mathrm{FDG}\right)$, a common tracer largely employed in oncology. New tracers of lung inflammation are now available.

\section{Inflammation Imaging with $\left[{ }^{18} \mathrm{~F}\right]$-FDG}

$\left[{ }^{18} \mathrm{~F}\right]-\mathrm{FDG}$, is a glucose analog, tracking cellular metabolic activity. $\left[{ }^{18} \mathrm{~F}\right]-$ FDG enters into the cells via glucose transporters (mainly GLUT-1), and is phosphorylated into $\left[{ }^{18} \mathrm{~F}\right]$-FDG-monophosphate by hexokinase. In tissue lacking glucose-6-dephosphorylase (such as the lung), $\left[{ }^{18} \mathrm{~F}\right]$-FDG-monophosphate is not further metabolized and accumulates into the cell to an extent depending on the activity level of hexokinase. Autoradiographic studies performed in different proinflammatory settings have shown that increased pulmonary $\left[{ }^{18} \mathrm{~F}\right]-\mathrm{FDG}$ uptake was relatively specific of neutrophils, even in situations where the majority of lung inflammatory cells were macrophages $[58,59]$. This relative specificity of $\left[{ }^{18} \mathrm{~F}\right]-$ FDG uptake to lung neutrophils has been attributed to a particular ability of these cells to upregulate their glucose metabolism in response to several pulmonary challenges with inflammatory stimuli, as compared to other cell types such as lung fibroblasts or macrophages [59]. Furthermore, it was later shown that neutrophils priming rather than neutrophils sequestration is the main determinant of regional pulmonary uptake of $\left[{ }^{18} \mathrm{~F}\right]-\mathrm{FDG}$ in lobar pneumonia and acute lung injury [60-62]. However, neutrophils depletion decreases lung $\left[{ }^{18} \mathrm{~F}\right]-\mathrm{FDG}$ uptake by only $50 \%$ to $70 \%$ in experimental models of acute lung injury [63, 64], suggesting that other cell types are involved in lung $\left[{ }^{18} \mathrm{~F}\right]$ FDG metabolism. Activated monocytes are potential candidates to explain neutrophils-independent increase of pulmonary $\left[{ }^{18} \mathrm{~F}\right]-\mathrm{FDG}$ uptake [65] in acute lung injury, among others. $\left[{ }^{18} \mathrm{~F}\right]-\mathrm{FDG}$ is then a non specific tracer of lung inflammation in ARDS, but with a predominant affinity for activated neutrophils. However, $\left[{ }^{18} \mathrm{~F}\right]-\mathrm{FDG}$ imaging with
PET may be particularly sensitive to detect lung inflammation, since increased $\left[{ }^{18} \mathrm{~F}\right]-\mathrm{FDG}$ uptake could be demonstrated in mild experimental models of acute lung injury, even though histopathological changes were not evident $[64,66]$.

Quantitative analysis of lung $\left[{ }^{18} \mathrm{~F}\right]-\mathrm{FDG}$ uptake is usually performed by computation of $\left[{ }^{18} \mathrm{~F}\right]-\mathrm{FDG}$ influx constant (Ki), either using Patlak graphical analysis $[67,68]$ or bicompartmental modeling [69]. Computation of standardized uptake value (SUV) is not an appropriate method to quantify $\left[{ }^{18} \mathrm{~F}\right]-\mathrm{FDG}$ accumulation within the lungs in ARDS, since it cannot differentiate between passive passage of tracer through damaged alveolar-capillary membrane from active tracer accumulation within inflammatory cells [69]. Another important issue in ARDS is related to the strong dependency of $\mathrm{Ki}$ on lung inflation. This can be taken into account by normalization using either $\left[{ }^{18} \mathrm{~F}\right]-\mathrm{FDG}$ distribution volume (one of the parameter of the models) [60], or tissue fraction assessed from density analysis of transmission scan [64] (Fig. 4). This issue is, however, controversial since Dr. Schuster's group has repeatedly observed a non significant effect of this correction, and argued against it by principle of parsimony $[62,69]$. However, these studies were performed in patients spontaneously breathing or during experimental lung injury with standardized ventilatory settings, and normalization for lung inflation is probably required when comparing groups with heterogeneous ventilatory strategies [64]. Another methodological issue of $\left[{ }^{18} \mathrm{~F}\right]-\mathrm{FDG}$ uptake computation in lung injury has recently been pointed out by Venegas' group [70]. The authors hypothesized that large pools of edematous tissue may be functionally away from inflammatory cells and developed a 3-compartment model including an extravascular and non cellular compartment, accumulating $\left[{ }^{18} \mathrm{~F}\right]-\mathrm{FDG}$ that will not be immediately available for phosphorylation. With this approach, curve fitting was significantly improved, when compared with the bi-compartmental model, particularly during the early phase following tracer injection, but $\mathrm{Ki}$ was not significantly affected in both smoke and ventilator-induced lung injury models [70]. Whether this new model will become a standard in ARDS deserves further investigations.

\section{PET Imaging Macrophage Kinetics}

Macrophage kinetics may be assessed with PET using $\left[{ }^{11} \mathrm{C}\right] \mathrm{R}-\mathrm{PK} 11195$, a tracer binding specifically to the peripheral benzodiazepine receptors present in a large number in macrophages, and also to a lesser extent in neutrophils and lung tissue [71, 72]. Resident macrophages, the main cell type present in alveolar spaces, play a pivotal role in modulation of lung inflammation during ARDS, by releasing inflammatory mediators triggering blood monocytes recruitment into the lungs, lung reparation and fibroproliferation. Increased $\left[{ }^{11}\right.$ C]R-PK11195 uptake have been reported in a mouse model of LPS-induced acute lung injury [73]. No study has been done in ARDS, but feasibility of detecting macrophage activity in human lungs with this technique has been demonstrated in COPD and asthma patients [72]. Interpretation of variation in $\left[{ }^{11} \mathrm{C}\right] \mathrm{R}-\mathrm{PK} 11195$ uptake is, however, not univocal, since reduced $\left[{ }^{11} \mathrm{C}\right] \mathrm{R}$ PK11195 uptake may indicate evolution towards lung fibrosis, as previously shown in scleroderma fibrosing 


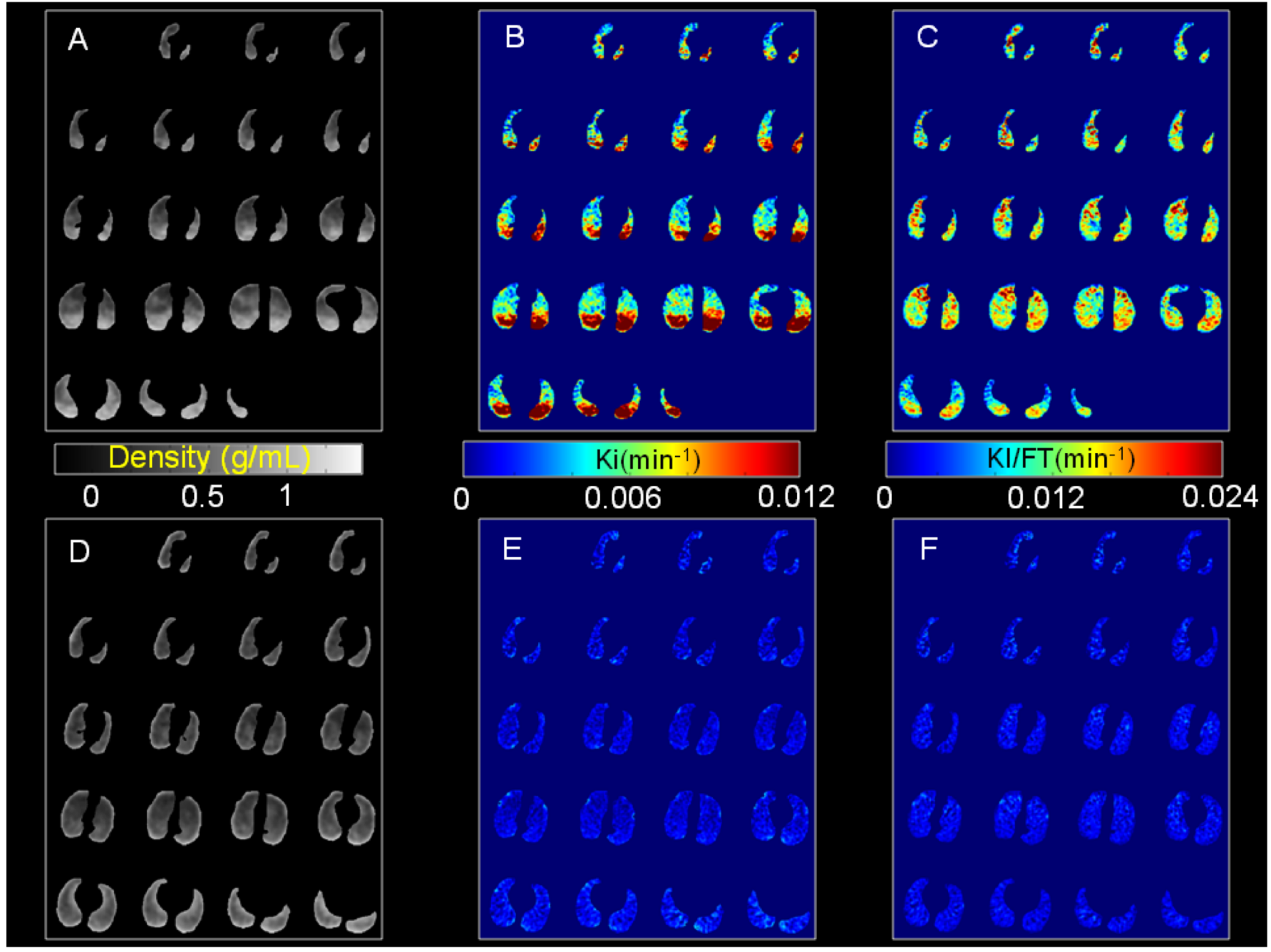

Fig. (4). Parametric images of lung density (panels A and D), ${ }^{18}$ F-FDG uptake (panels $\mathbf{B}$ and $\mathbf{E}$ ) and ${ }^{18}$ F-FDG uptake normalized by tissue fraction (panels $\mathbf{C}$ and $\mathbf{F}$ ) in a lung injured pig (upper panels) and a normal pig (lower panels) lying supine. As clearly shown, ${ }^{18} \mathrm{~F}-\mathrm{FDG}$ uptake (Ki) is very low in normal pig (panel E), while lung injured pig exhibits diffuse increase in cellular metabolic activity, with a clear predominance in the dorsal dependent lung regions (panel B). However, Ki normalization with tissue fraction (FT) has a huge effect on images (panel $\mathbf{C}$ ), and appears relatively homogeneous.

alveolitis [74]. Obviously additional studies are required in ARDS patients to confirm the potential of this tracer.

\section{New PET Tracers Targeting Lung Inflammation and Fibrosis}

New ${ }^{64} \mathrm{CU}$-labeled peptides targeting neutrophils receptors are now currently available. cFLFLFK-PEG- $-{ }^{64} \mathrm{Cu}$ and cFLFLF-PEG- ${ }^{64} \mathrm{Cu}$ are specific antagonists of the formyl peptide receptor, and have been shown to specifically probe lung inflammation from neutrophils in a mouse model of bacterial pneumonia $[75,76]$. I.V. injection of $\left[{ }^{18} \mathrm{~F}\right]-\mathrm{FDG}$ labeled leucocytes has recently been proposed to track inflammation and/or infection with PET [77]. This method may give different insights on lung inflammation, in the sense that it detects the presence of neutrophils, as opposed to neutrophils activation with conventional i.v. $\left[{ }^{18} \mathrm{~F}\right]-\mathrm{FDG}$. To date, none of these new tracers has been tested in ARDS.

Pulmonary fibrosis is a major issue in non-resolving ARDS [78], and may be linked to an imbalance between collagen synthesis and extracellular matrix degradation by matrix metalloproteinases. Collagen synthesis may be non- invasively quantified in animal models using ${ }^{18} \mathrm{~F}$-labeled proline analogs [79], while extracellular matrix degradation may be assessed with PET by ${ }^{18} \mathrm{~F}$-labelled metalloproteinase inhibitors $[80,81]$. While animal studies report promising results [79], preliminary reports in idiopathic pulmonary fibrosis are disappointing [82] and studies in experimental lung injury or ARDS are lacking.

\section{CONTRIBUTION OF PET STUDIES TO ARDS PHYSIOPATHOLOGY}

To date, 7 studies done in humans with ARDS have been published involving a total of 49 patients (Table 1). Several studies have confirmed that pulmonary vascular permeability was high in ARDS patients, relative to normal human volunteers $[16,83,84]$. However, the regional correlation between vascular permeability and EVLW was relatively weak [83], and most patients exhibit diffuse increased vascular permeability, even in lung regions with normal density and EVLW [85], suggesting that lung density and EVLW are inadequate markers of ARDS. Furthermore, while a vertical gradient of EVD was consistently found (the 
Table 1.

\begin{tabular}{|c|c|c|c|c|}
\hline First Author & Year of Publication & PET Tracer & PET Measurement & Number of ALI/ARDS Patients \\
\hline \hline Mintun [16] & 1987 & ${ }^{68} \mathrm{Ga}$-transferrin & PVP & 2 \\
\hline Calandrino [83] & 1988 & ${ }^{68} \mathrm{Ga}$-transferrin & EVD, PVP & 15 \\
\hline Kaplan [84] & 1991 & ${ }^{68} \mathrm{Ga}$-transferrin & EVD, PVP & 8 \\
\hline Sandiford [85] & 1995 & ${ }^{68} \mathrm{Ga}$-transferrin & EVD, PVP & $8^{*}$ \\
\hline Schuster [87] & 2002 & $\mathrm{H}_{2}^{15} \mathrm{O}$ & PBF & 9 \\
\hline Schuster [86] & 2002 & ${ }^{68} \mathrm{Ga}-$ transferrin & PVP & $5 \dagger$ \\
\hline Bellani [88] & 2009 & ${ }^{18} \mathrm{~F}-\mathrm{FDG}$ & Inflammation & 10 \\
\hline
\end{tabular}

* Studies by Sandiford and Kaplan report data from the same patients.

$\uparrow$ This number represents only a fraction of the patients who were effectively studied with PET in this investigation.

$\mathrm{ALI}=$ acute lung injury; EVD = extravascular density; FDG = fluorodeoxyglucose; $\mathrm{PBF}=$ pulmonary blood flow; $\mathrm{PET}=$ positron emission tomography; $\mathrm{PVP}=$ pulmonary vascular permeability.

most edematous regions being in the dependent parts of the lung), no vertical gradient was found with regard to pulmonary vascular permeability [85]. This result is a strong argument favoring the sponge model proposed by Gattinoni, who theorized that increased permeability and edema have an even distribution in ARDS, but increased lung mass cause lung to collapse under his own weight [3].

As expected, high pulmonary vascular permeability is, however, non specific of ARDS, and has also been observed in patients with pneumonia [84]. Moreover, in a more recent study combining PET and mobile- $\gamma$-scintigraphy data [86], there was considerable overlap regarding pulmonary vascular permeability between patients with hydrostatic and non-hydrostatic pulmonary edema, suggesting that structural damage of the alveolar-capillary membrane may also exist in hydrostatic pulmonary edema, as demonstrated by West et al. as the stress capillary failure (West, 1992 \#53683). Taken together, these data have the following implications. First, they clearly demonstrate that increased vascular permeability, as assessed by nuclear medicine or other techniques, are not reliable to improve diagnosis performance of classical criteria of ARDS [4]. Second, defining ARDS properly would require the assessment of different components, increased vascular permeability, increased EVLW, increased lung inflammation, all of them can be achieved with PET. It has been claimed that current definitions of ARDS lack of sensitivity and specificity. Therefore, PET should be a very well suited mean to make a step forward in the definition of ARDS patients and to propose a more subtle characterization of ARDS patients than that is done currently.

Improved knowledge of gas exchange physiopathology in ARDS patients is another important contribution of PET imaging. Schuster et al. did not find any difference in ventral-to-dorsal perfusion distribution between normal subjects and supine patients with either hydrostatic or non hydrostatic pulmonary edema, despite an increase in TLW predominating in the dorsal regions in patients [87]. This suggests that hypoxic pulmonary vasoconstriction is at least partially blunted in ARDS patients.

More recently, Bellani et al. have shown that lung $\left[{ }^{18} \mathrm{~F}\right]-$ FDG uptake was markedly increased in ARDS patients, relative to control subjects, but with a great variability in intensity and spatial distribution between patients [88]. Furthermore, $\left[{ }^{18} \mathrm{~F}\right]$-FDG uptake of normally aerated regions in ARDS patients was much higher than in controls, suggesting than morphologically normal lung areas, as assessed with CT, may nevertheless exhibit an intense inflammation.

This discrepancy between lung morphological imaging and functional imaging was also found in patients at risk of ARDS following chest trauma [89]. In contrast to patients with favorable respiratory outcome, those who subsequently develop ARDS exhibit diffuse lung $\left[{ }^{18} \mathrm{~F}\right]-\mathrm{FDG}$ uptake including normally aerated regions. This suggests that PET may have potential to identify the early stage of ARDS, even before ARDS criteria are met.

\section{CONCLUSION}

In conclusion, PET imaging has provided unique information on the physiopathology of ARDS, and will certainly provide additional data with emergence of new tracers widening the field of the respiratory findings that can be tracked by PET. To date, PET remains an invaluable research tool in ARDS patients, but its utility in the clinical setting remains to be proven.

\section{REFERENCES}

[1] Phua J, Badia JR, Adhikari NK, et al. Has mortality from acute respiratory distress syndrome decreased over time?: A systematic review. Am J Respir Crit Care Med 2009; 179: 220-7.

[2] Ware LB, Matthay MA. The acute respiratory distress syndrome. N Engl J Med 2000; 342: 1334-49.

[3] Gattinoni L, Caironi P, Pelosi P, Goodman LR. What Has Computed Tomography Taught Us about the Acute Respiratory Distress Syndrome? Am J Respir Crit Care Med 2001; 164: 170111.

[4] Bernard GR, Artigas A, Brigham KL, et al. Report of the American-European consensus conference on ARDS: definitions, mechanisms, relevant outcomes and clinical trial coordination. The Consensus Committee. Intensive Care Med 1994; 20: 225-32.

[5] Schuster DP. Positron emission tomography: theory and its application to the study of lung disease. Am Rev Respir Dis 1989; 139: 818-40

[6] Rhodes CG, Hughes JM. Pulmonary studies using positron emission tomography. Eur Respir J 1995; 8: 1001-17.

[7] Schuster DP. The evaluation of lung function with PET. Semin Nucl Med 1998; 28: 341-51.

[8] Musch G, Venegas JG. Positron emission tomography imaging of regional pulmonary perfusion and ventilation. Proc Am Thorac Soc 2005; $2: 522-7$. 
[9] Harris RS, Schuster DP. Visualizing lung function with positron emission tomography. J Appl Physiol 2007; 102: 448-58.

[10] Chen DL, Richard JC, Schuster DP. Molecular imaging of enzyme function in lungs. Methods Enzymol 2004; 385: 315-33.

[11] Brun-Buisson C, Minelli C, Bertolini G, et al. Epidemiology and outcome of acute lung injury in European intensive care units. Results from the ALIVE study. Intensive Care Med 2004; 30: 5161.

[12] Laffon E, Cazeau AL, Monet A, et al. The effect of renal failure on ${ }^{18}$ F-FDG uptake: a theoretic assessment. J Nucl Med Technol 2008; 36: $200-2$.

[13] Mintun MA, Ter-Pogossian MM, Green MA, Lich LL, Schuster DP. Quantitative measurement of regional pulmonary blood flow with positron emission tomography. J Appl Physiol 1986; 60: 31726.

[14] Schuster DP, Kaplan JD, Gauvain K, Welch MJ, Markham J. Measurement of regional pulmonary blood flow with PET. J Nucl Med 1995; 36: 371-7.

[15] Musch G, Layfield JDH, Harris RS, et al. Topographical distribution of pulmonary perfusion and ventilation, assessed by PET in supine and prone humans. J Appl Physiol 2002; 93: 184151.

[16] Mintun MA, Dennis DR, Welch MJ, Mathias CJ, Schuster DP. Measurements of pulmonary vascular permeability with PET and gallium-68 transferrin. J Nucl Med 1987; 28: 1704-16.

[17] Richard JC, Janier M, Decailliot F, et al. Comparison of positron emission tomography with radioactive microspheres to assess pulmonary blood flow. J Nucl Med 2002; 43: 1063-71

[18] Markham J, Schuster DP. Effects of non ideal input functions on PET measurements of pulmonary blood flow. J Appl Physiol 1992; 72: 2495-500.

[19] Galletti GG, Venegas JG. Tracer kinetic model of regional pulmonary function using positron emission tomography. J Appl Physiol 2002; 93: 1104-14.

[20] Richter T, Bellani G, Scott Harris R, et al. Effect of prone position on regional shunt, aeration, and perfusion in experimental acute lung injury. Am J Respir Crit Care Med 2005; 172: 480-7.

[21] O'Neill K, Venegas JG, Richter T, et al. Modeling kinetics of infused ${ }^{13} \mathrm{NN}$-saline in acute lung injury. J Appl Physiol 2003; 95: 2471-84.

[22] Willey-Courand DB, Harris RS, Galletti GG, Hales CA, Fischman A, Venegas JG. Alterations in regional ventilation, perfusion, and shunt after smoke inhalation measured by PET. J Appl Physiol 2002; 93: 1115-22.

[23] Senda M, Murata K, Itoh H, Yonekura Y, Torizuka K. Quantitative evaluation of regional pulmonary ventilation using PET and nitrogen-13 gas. J Nucl Med 1986; 27 : 268-73.

[24] Mijailovich SM, Treppo S, Venegas JG. Effects of lung motion and tracer kinetics corrections on PET imaging of pulmonary function. J Appl Physiol 1997; 82: 1154-62.

[25] Valind SO, Rhodes CG, Brudin LH, Jones T. Measurements of regional ventilation pulmonary gas volume: theory and error analysis with special reference to positron emission tomography. J Nucl Med 1991; 32: 1937-44.

[26] Treppo S, Mijailovich SM, Venegas JG. Contributions of pulmonary perfusion and ventilation to heterogeneity in $\mathrm{V}(\mathrm{A}) / \mathrm{Q}$ measured by PET. J Appl Physiol 1997; 82: 1163-76.

[27] Musch G, Harris RS, Vidal Melo MF, et al. Mechanism by which a sustained inflation can worsen oxygenation in acute lung injury. Anesthesiology 2004; 100: 323-30.

[28] Richard JC, Janier M, Lavenne F, et al. Quantitative assessment of regional alveolar ventilation and gas volume using $\left[{ }^{13} \mathrm{~N}\right] \mathrm{N}_{2}$ washout and positron emission tomography. J Nucl Med 2005; 46: 1375-83.

[29] Vidal Melo MF, Layfield D, Harris RS, et al. Quantification of regional ventilation-perfusion ratios with PET. J Nucl Med 2003; 44: 1982-91.

[30] Rhodes CG, Valind SO, Brudin LH, et al. Quantification of regional V/Q ratios in humans by use of PET. II. Procedure and normal values. J Appl Physiol 1989; 66: 1905-13.

[31] Rhodes CG, Valind SO, Brudin LH, Wollmer PE, Jones T, Hughes JM. Quantification of regional V/Q ratios in humans by use of PET. I. Theory. J Appl Physiol 1989; 66: 1896-904.

[32] Musch G, Venegas JG. Positron emission tomography imaging of regional lung function. Minerva Anestesiol 2006; 72: 363-7.
[33] Vidal Melo MF, Harris RS, Layfield D, Musch G, Venegas JG. Changes in regional ventilation after autologous blood clot pulmonary embolism. Anesthesiology 2002; 97: 671-81.

[34] Gattinoni L, Pesenti A. ARDS: the non-homogenous lung; facts and hypothesis. Intensive Crit Care Dig 1987; 6: 1-4.

[35] Tremblay LN, Slutsky AS. Ventilator-induced lung injury: from the bench to the bedside. Intensive Care Med 2006; 32: 24-33.

[36] Brudin LH, Rhodes CG, Valind SO, Jones T, Jonson B, Hughes JM. Relationships between regional ventilation and vascular and extravascular volume in supine humans. J Appl Physiol 1994; 76: 1195-204.

[37] Schuster DP, Marklin GF, Mintun MA, Ter-Pogossian MM. PET measurement of regional lung density: 1. J Comput Assist Tomogr 1986; 10: 723-9.

[38] Richard JC, Le Bars D, Costes N, et al. Alveolar recruitment assessed by positron emission tomography during experimental acute lung injury. Intensive Care Med 2006; 32: 1889-94.

[39] Gattinoni L, Pesenti A, Bombino M, et al. Relationships between lung computed tomographic density, gas exchange, and PEEP in acute respiratory failure. Anesthesiology 1988; 69: 824-32.

[40] Gattinoni L, Pelosi P, Crotti S, Valenza F. Effects of positive endexpiratory pressure on regional distribution of tidal volume and recruitment in adult respiratory distress syndrome. Am J Respir Crit Care Med 1995; 151: 1807-14.

[41] Musch G, Bellani G, Vidal Melo MF, et al. Relation between shunt, aeration, and perfusion in experimental acute lung injury. Am J Respir Crit Care Med 2008; 177: 292-300.

[42] Sakka SG, Klein M, Reinhart K, Meier-Hellmann A. Prognostic value of extravascular lung water in critically ill patients. Chest 2002; 122: 2080-6.

[43] Schuster DP, Markham J, Welch MJ. Positron emission tomography measurements of pulmonary vascular permeability with Ga-68 transferrin or C-11 methylalbumin. Crit Care Med 1998; 26: 518-25.

[44] Velazquez M, Weibel ER, Kuhn C, 3rd, Schuster DP. PET evaluation of pulmonary vascular permeability: a structure-function correlation. J Appl Physiol 1991; 70: 2206-16.

[45] Hamvas A, Kaplan JD, Markham J, Schuster DP. The effects of regional pulmonary blood flow on protein flux measurements with PET. J Nucl Med 1992; 33: 1661-8.

[46] Mintun MA, Warfel TE, Schuster DP. Evaluating pulmonary vascular permeability with radiolabeled proteins: an error analysis. J Appl Physiol 1990; 68: 1696-706.

[47] Schuster DP, Mintun MA, Green MA, Ter-Pogossian MM. Regional lung water and hematocrit determined by positron emission tomography. J Appl Physiol 1985; 59: 860-8.

[48] Brudin LH, Valind SO, Rhodes CG, Turton DR, Hughes JM. Regional lung hematocrit in humans using positron emission tomography. J Appl Physiol 1986; 60: 1155-63.

[49] Velazquez M, Schuster DP. Effect of regional pulmonary blood flow on extravascular lung water measurements with PET. J Appl Physiol 1988; 65: 1267-73.

[50] Schuster DP, Marklin GF, Mintun MA. Regional changes in extravascular lung water detected by positron emission tomography. J Appl Physiol 1986; 60: 1170-8.

[51] Velazquez M, Haller J, Amundsen T, Schuster DP. Regional lung water measurements with PET: accuracy, reproducibility, and linearity. J Nucl Med 1991; 32: 719-25.

[52] Rhodes CG, Wollmer P, Fazio F, Jones T. Quantitative measurement of regional extravascular lung density using positron emission and transmission tomography. J Comput Assist Tomogr 1981; 5: 783-91

[53] Brudin LH, Rhodes CG, Valind SO, Wollmer P, Hughes JM. Regional lung density and blood volume in nonsmoking and smoking subjects measured by PET. J Appl Physiol 1987; 63: 1324-34.

[54] Nehmeh SA, Erdi YE. Respiratory motion in positron emission tomography/computed tomography: a review. Semin Nucl Med 2008; 38: 167-76.

[55] Townsend DW. Positron emission tomography/computed tomography. Semin Nucl Med 2008; 38: 152-66.

[56] Ranieri VM, Suter PM, Tortorella C, et al. Effect of mechanical ventilation on inflammatory mediators in patients with acute respiratory distress syndrome: a randomized controlled trial. JAMA 1999; 282: 54-61. 
[57] No Authors Listed. Ventilation with lower tidal volumes as compared with traditional tidal volumes for acute lung injury and the acute respiratory distress syndrome. N Engl J Med 2000; 342: 1301-8.

[58] Jones HA, Clark RJ, Rhodes CG, Schofield JB, Krausz T, Haslett C. In vivo measurement of neutrophil activity in experimental lung inflammation. Am J Respir Crit Care Med 1994; 149: 1635-9.

[59] Jones HA, Schofield JB, Krausz T, Boobis AR, Haslett C. Pulmonary fibrosis correlates with duration of tissue neutrophil activation. Am J Respir Crit Care Med 1998; 158: 620-8.

[60] Jones HA, Sriskandan S, Peters AM, et al. Dissociation of neutrophil emigration and metabolic activity in lobar pneumonia and bronchiectasis. Eur Respir J 1997; 10: 795-803.

[61] Hartwig W, Carter EA, Jimenez RE, et al. Neutrophil metabolic activity but not neutrophil sequestration reflects the development of pancreatitis-associated lung injury. Crit Care Med 2002; 30: 207582.

[62] Chen DL, Rosenbluth DB, Mintun MA, Schuster DP. FDG-PET imaging of pulmonary inflammation in healthy volunteers after airway instillation of endotoxin. J Appl Physiol 2006; 100(5): $1602-9$.

[63] Zhou Z, Kozlowski J, Goodrich AL, Markman N, Chen DL, Schuster DP. Molecular imaging of lung glucose uptake after endotoxin in mice. Am J Physiol Lung Cell Mol Physiol 2005; 289: L760-8.

[64] Musch G, Venegas JG, Bellani G, et al. Regional gas exchange and cellular metabolic activity in ventilator-induced lung injury. Anesthesiology 2007; 106: 723-35.

[65] Paik JY, Lee KH, Choe YS, Choi Y, Kim BT. Augmented ${ }^{18}$ F-FDG uptake in activated monocytes occurs during the priming process and involves tyrosine kinases and protein kinase C. J Nucl Med 2004; 45: 124-8.

[66] Zhou Z, Kozlowski J, Schuster DP. Physiologic, biochemical, and imaging characterization of acute lung injury in mice. Am J Respir Crit Care Med 2005; 172: 344-51.

[67] Patlak CS, Blasberg RG. Graphical evaluation of blood-to-brain transfer constants from multiple-time uptake data. Generalizations. J Cereb Blood Flow Metab 1985; 5: 584-90.

[68] Patlak CS, Blasberg RG, Fenstermacher JD. Graphical evaluation of blood-to-brain transfer constants from multiple-time uptake data. J Cereb Blood Flow Metab 1983; 3: 1-7.

[69] Chen DL, Mintun MA, Schuster DP. Comparison of methods to quantitate ${ }^{18} \mathrm{~F}$-FDG uptake with PET during experimental acute lung injury. J Nucl Med 2004; 45: 1583-90.

[70] Schroeder T, Vidal Melo MF, Musch G, Harris RS, Venegas JG, Winkler T. Modeling pulmonary kinetics of 2-deoxy-2- $\left.{ }^{18} \mathrm{~F}\right]$ fluoroD-glucose during acute lung injury. Acad Radiol 2008; 15: 763-75.

[71] Zavala F, Lenfant M. Benzodiazepines and PK 11195 exert immunomodulating activities by binding on a specific receptor on macrophages. Ann N Y Acad Sci 1987; 496: 240-9.

[72] Jones HA, Marino PS, Shakur BH, Morrell NW. In vivo assessment of lung inflammatory cell activity in patients with COPD and asthma. Eur Respir J 2003; 21: 567-73.

[73] Hardwick MJ, Chen MK, Baidoo K, Pomper MG, Guilarte TR. In vivo imaging of peripheral benzodiazepine receptors in mouse lungs: a biomarker of inflammation. Mol Imaging 2005; 4: 432-8.
[74] Branley HM, du Bois RM, Wells AU, Jones HA. PET scanning of macrophages in patients with scleroderma fibrosing alveolitis. Nucl Med Biol 2008; 35: 901-9.

[75] Zhang Y, Kundu B, Fairchild KD, et al. Synthesis of novel neutrophil-specific imaging agents for Positron Emission Tomography (PET) imaging. Bioorg Med Chem Lett 2007; 17: 6876-8.

[76] Locke LW, Chordia MD, Zhang Y, et al. A novel neutrophilspecific PET imaging agent: cFLFLFK-PEG- ${ }^{64} \mathrm{Cu}$. J Nucl Med 2009; 50: 790-7.

[77] Rini JN, Bhargava KK, Tronco GG, et al. PET with FDG-labeled leukocytes versus scintigraphy with ${ }^{111}$ In-oxine-labeled leukocytes for detection of infection. Radiology 2006; 238: 978-87.

[78] Papazian L, Doddoli C, Chetaille B, et al. A contributive result of open-lung biopsy improves survival in acute respiratory distress syndrome patients. Crit Care Med 2007; 35: 755-62.

[79] Wallace WE, Gupta NC, Hubbs AF, et al. Cis-4-[(18) F]fluoro-Lproline PET imaging of pulmonary fibrosis in a rabbit model. $\mathrm{J}$ Nucl Med 2002; 43: 413-20.

[80] Breyholz HJ, Wagner S, Levkau B, Schober O, Schafers M, Kopka K. A ${ }^{18}$ F-radiolabeled analogue of CGS $27023 \mathrm{~A}$ as a potential agent for assessment of matrix-metalloproteinase activity in vivo. Q J Nucl Med Mol Imaging 2007; 51: 24-32.

[81] Wagner S, Breyholz HJ, Holtke C, et al. A new ${ }^{18}$ F-labelled derivative of the MMP inhibitor CGS 27023A for PET: radiosynthesis and initial small-animal PET studies. Appl Radiat Isot 2009; 67: 606-10.

[82] Lavalaye J, Grutters JC, van de Garde EM, et al. Imaging of fibrogenesis in patients with idiopathic pulmonary fibrosis with cis4-[ ${ }^{[18)}$ F]-Fluoro-L: -proline PET. Mol Imaging Biol 2009; 11: 1237.

[83] Calandrino FS, Jr., Anderson DJ, Mintun MA, Schuster DP Pulmonary vascular permeability during the adult respiratory distress syndrome: a positron emission tomographic study. Am Rev Respir Dis 1988; 138: 421-8.

[84] Kaplan JD, Calandrino FS, Schuster DP. A positron emission tomographic comparison of pulmonary vascular permeability during the adult respiratory distress syndrome and pneumonia. Am Rev Respir Dis 1991; 143: 150-4.

[85] Sandiford P, Province MA, Schuster DP. Distribution of regional density and vascular permeability in the adult respiratory distress syndrome. Am J Respir Crit Care Med 1995; 151: 737-42.

[86] Schuster DP, Stark T, Stephenson J, Royal H. Detecting lung injury in patients with pulmonary edema. Intensive Care Med 2002; 28: 1246-53.

[87] Schuster DP, Anderson C, Kozlowski J, Lange N. Regional pulmonary perfusion in patients with acute pulmonary edema. J Nucl Med 2002; 43: 863-70.

[88] Bellani G, Messa C, Guerra L, et al. Lungs of patients with acute respiratory distress syndrome show diffuse inflammation in normally aerated regions: a $\left[{ }^{18} \mathrm{~F}\right]$-fluoro-2-deoxy-D-glucose PET/CT study. Crit Care Med 2009; 37: 2216-22.

[89] Rodrigues RS, Miller PR, Bozza FA, et al. FDG-PET in patients at risk for acute respiratory distress syndrome: a preliminary report. Intensive Care Med 2008; 34: 2273-8. 